ISSUES AND INNOVATIONS IN NURSING PRACTICE

\title{
Expert nurses' use of implicit memory in the care of patients with Alzheimer's disease
}

\author{
Kader Parahoo BA PhD RMN \\ Professor in Nursing and Health Research, Institute of Nursing Research, University of Ulster, Co. Londonderry, UK
}

Ann L. Whall PhD RN FAAN

Professor and Associate Director, The University of Michigan School of Nursing, Ann Arbor, Michigan, USA

Kathleen Colling PhD RN

Professor, The University of Michigan School of Nursing, Ann Arbor, Michigan, USA

Deborah Nusbaum MS RN NP

Women's Health Practitioner, The University of Michigan School of Nursing, Ann Arbor, Michigan, USA

Accepted for publication 29 November 2005

Correspondence:

Kader Parahoo,

Institute of Nursing Research,

University of Ulster,

Cromore Road,

Co. Londonderry BT52 1SA,

UK.

E-mail:ak.parahoo@ulster.ac.uk
PARAHOO K., WHALL A.L., COLliNG K. \& NUSBAUM D. (2006) Journal of Advanced Nursing 54(5), 563-571

Expert nurses' use of implicit memory in the care of patients with Alzheimer's disease

Aim. This paper reports a study exploring expert nurses' use of implicit memory in the care of people with Alzheimer's disease.

Background. Although research has shown the benefits of preserving and using implicit memory in patients with Alzheimer's disease, the literature shows little evidence of how nurses, in particular expert ones, make use of implicit memory with this client group in clinical practice.

Method. Semi-structured interviews were carried out with a purposive sample of eight nurses (four from Michigan, United States of America and four from Northern Ireland) in 2004. The interviews focused on specific issues, but were deliberately flexible to allow participants to tell their stories as well. A nine-step data analysis process was developed based on a synthesis of methods used by other researchers. Findings. According to the expert nurses interviewed, the effective and meaningful use of the implicit memory of patients with Alzheimer's disease in achieving positive outcomes depended on 'knowing the patient', 'working within the patient's worldview' and 'using sensitive and patient-centred interactional skills'. They explained how their use of implicit memory (drawing from a range of knowledge sources) was underpinned by reflective practice.

Conclusion. The findings provide a positive profile of expert nurses' use of implicit memory of patients with Alzheimer's disease; however, their use of theoretical and research knowledge could be improved. There is also a need to test interventions based on the use of implicit memories.

Keywords: Alzheimer's disease, dementia, expert nurses, implicit memory, interviews, reflective practice, research report 


\section{Introduction}

The worldwide continuing rise in the number of older people has been followed by an increase in the prevalence of Alzheimer's disease, and this trend is set to continue. The challenge for carers is how to care for these people, who tend to exhibit behaviours such as restlessness, wandering, asking repetitive questions, shouting and lack of inhibition. The disease is associated in about $50 \%$ of cases with agitation, aggression and hyperactivity (Burke \& Morgenlander 1999). Much of this can be prevented by appropriate actions such as activity programmes, behavioural modification and environmental manipulation (Lai \& Arthur 2003).

Dementia, in particular the type associated with Alzheimer's disease, presents an enormous challenge for carers. To maximize the quality of life of sufferers and carers and to make efficient use of scarce resources, healthcare professionals need to reflect on their practices and to ensure that their interventions are effective.

\section{Background}

Unusual behaviour in people with Alzheimer's disease can be the result of a number of stressful factors, including memory loss. Norberg (1996) explains that, if a patient's condition does not allow her (sic) 'to interpret what was going on in the present she would have to search through her brain for a memory revealing the same emotion she was experiencing as she lay confined in bed' (p. 106). Therefore, patients use their past experiences to make sense, and cope with the present. Confronting patients' 'reality' leaves them in a world lost between the past and the present, in a state of helplessness and despair, and can lead to uncharacteristic behaviour on the part of patients (and nurses). Inability of nurses to prevent aggressive or overactive behaviour can lead to inappropriate interventions, such as over-use of medication, or even to more harmful practices, such as abuse and neglect (Eriksson \& Saveman 2002).

The experience and process of caring for people with Alzheimer's disease and dementia have been the focus of a number of studies. Hallberg and Norberg (1990) explored staff interpretations of the experience behind vocally disruptive behaviour in patients with severe dementia. The experienced caregivers interviewed reported that caring for these patients was an extreme burden. They had to cope with the patients' emotional affliction, interpret their behaviour and communicate in a way that made life easier for the patients. Hallberg and Norberg (1990) recommended that regular supervision to support these caregivers be provided.
Berg et al. (1998), in their study of nurses' reflections about dementia care, found that caring for people with severe dementia involved a delicate interpretive work. The participants also described how at the beginning they were 'unprepared, shocked and unaware of what they would have to face and what was expected of them, to the time when they felt more experienced and confident' (Berg et al. 1998, p276).

Jansson and Norberg (1992) interviewed 20 'experienced and good' nurses about the feeding of a patient with severe dementia who showed refusal-like feeding behaviour. They reported that nurses 'justified their ranking of ethical principles by stressing their personal experience rather than using philosophical arguments' (p. 225). The 'mature ethical reasoning' of these nurses was reflected in the fact that they did not use the ethical principles 'one by one' but integrated them as a 'whole' in their practice.

Patients' behaviour can be interpreted differently by nurses and by patients themselves. According to Powers (2004), 'resistance to care' describes the caregiver's experience and not the patient's. The patient may be experiencing the effects of their disease, an emotional state, a physical condition or some environmental disturbance or distraction (Powers 2004).

\section{The nature of implicit memory in dementia}

Graf and Masson (1993), in a summary of research on implicit (IM) and explicit memory (EM), defined them on the basis of conscious recall. IM has been called 'unconscious memory' and is seen as the type of memory used to function unconsciously and is not mediated by conscious intention. An example frequently given of IM is the ability to drive a car to a familiar destination without conscious recall of each and every stop and turn. EM is the ability to identify on demand the current date, time and place, or to interpret a written message. Camus et al. (2001) found that EM in patients with Alzheimer's disease dramatically decreases, while De Vreese et al. (2001) reported that the IM of procedures such as combing one's hair remains relatively intact throughout the progression of Alzheimer's disease.

Implicit memory has been further classified into procedural and emotional memory. To put it simply, habits and skills learnt prior to injury or disease onset are to some extent spared by the degeneration process of disease, and thus patients with dementia or amnesia can maintain previously developed habits and skills (Bachevalier \& Mishkin 1984). Thus, previously-learnt skills are stored and can be retrieved by stimulus cues through associative recall and stimulusresponse mechanisms (Mishkin \& Petri 1984). For example, presenting a patient with dementia (who was a flutist) with a flute can trigger procedural memory and may result in the 
person using it to play a tune. Emotional memory is a type of memory that includes feelings or affect related to, or surrounding, specific events or happenings. For example, the smell of roast turkey may trigger the memory of a previous Christmas that has particular significance for the person. The smell (or other visual or auditory cues) seems to activate the amygdala (Le Doux 1993) and bring forth experiences or memories that can be either positive or negative (Son et al. 2002). Finally, priming is the strategy or process of using props to bring to the fore the different types of IM.

A number of studies have investigated IMs and how people with dementia perform tasks associated with IM (Christensen \& Birrell 1991, De Vreese et al. 2001). Others have evaluated the effects of priming on recall and functional ability. Slizewski (1998) found that a person's (with Alzheimer's disease) ability to drink from a cup, comb their hair and/or brush their teeth was preserved so long as the utensils for these procedures (the primers) were handed to them, and a request was made along with imitative motions. Halpern and O'Connor (2000) suggested that visual priming might be more powerful in the functioning of IM than auditory stimuli alone, while Verfaellie et al. (2000) found that using auditory priming with patients Alzheimer's disease increased functional ability. So far, the literature shows little evidence of how nurses, in particular expert ones, make use of patients' IM in clinical practice.

\section{The study}

\section{Aim}

The aim of this study was to explore expert nurses' use of IM in the care of people with Alzheimer's disease.

\section{Design}

A cross-sectional interview study was carried out with a purposive sample of experienced nurses. Data were gathered in 2004.

Borrowing from Benner (1984), 'expert nurses' were defined as those with at least 5 years' experience, currently engaged in direct care of people with Alzheimer's disease and who are recognized by their peers as highly skilled technician's. They should also possess a relevant first-level nursing qualification.

\section{Participants}

A purposive sample of eight nurses [three men and five women; four from Michigan, United States of America (USA) and four from Northern Ireland (NI)] participated. Clinical managers working in this clinical field referred the participants to this study.

\section{Methods}

A semi-structured interview format was used to focus participants on specific issues. However, the interview was deliberately flexible to allow them to tell their stories as well. To help them to focus on their experiences of caring for patients in these situations, participants were asked the following questions:

- Can you explain how you may have used the 'procedural or unconscious memory' of the person with dementia during caregiving? If yes, please give us a brief example.

- To what extent do you focus 'back and forth' between the whole situation and particular aspects of the situation?

- Do you during such events intentionally focus upon theories that may be helpful?

In the introduction to the interview, we explained its purpose, defined the terms 'implicit memory', 'explicit memory' and gave examples of these. Participants were first asked to give an example of their use of these memories. This led to further questions from the interviewer. A narrative approach was used in which participants could tell their stories with little interruption from the interviewer.

Each interview lasted approximately 1 hour. Six were carried by AW and two by KP.

\section{Ethical considerations}

Approval for this study was obtained from the relevant ethics committees in each country. After giving an explanation of what the study entails and assurances of confidentiality, each participant was asked to sign a consent form. With the agreement of participants, all interviews were tape-recorded.

\section{Data analysis}

Data analysis approaches involving nine steps was developed as a result of a synthesis of the methods used by Colaizzi (1978), Benner (1984), Giorgi (1985) and van Kaam (1966). These three approaches are commonly used in the analysis of narrative texts. The rationale for synthesizing them was to agree on a procedure with which the research team, based on their research expertise, was most comfortable. The following steps were adopted:

- Listen to the tape and correct any errors in the transcript.

- Carefully read all of the interviewee's descriptions in order to acquire a 'feeling' for them. 
- Independent and, later, consensual interpretation of all aspects of text (e.g. other themes).

- Return again to the text and extract significant themes. Spell out meanings of each.

- Research team meets to discuss interpretations.

- Organize formulated meanings into clustered themes.

- Refer clusters of themes back to the original text to validate them.

- Interpretive analysis on the three levels described: paradigms, exemplars and themes.

- Synthesize all of the transformed units into consistent statements regarding the participant's experiences.

Each transcript was analysed by two researchers (one in the USA and one in NI). Similarities and differences were identified and discussed via e-mails and telephone calls.

The 'truth value' of the data, which is determined by how much participants recognize their story in the researcher's analysis of their experience (Morse \& Field 1996), was considered important. During and immediately after interview, participants were given feedback on what the researcher thought they said. If participants felt they were misunderstood, clarification was sought. Differences in interpretations of the data by the research team were resolved by discussion.

\section{Findings}

The eight participants provided a wealth of data on their use of IM (both emotional and procedural) in coping with the unusual behaviour of these patients. However, they did not use these terminologies; instead they constantly referred to 'short-term' and 'long-term' memory. Some participants had difficulty in understanding what terms like emotional memory, procedural memory or priming meant. Nonetheless, all gave examples of the use of these types of memories and of their strategies in using them. Below are two examples of the use of IM.

\section{Example 1}

A patient who perceived laundry (bed sheets, night clothes, etc.) to be 'hay' put them into bags and stacked them against the wall. One nurse later engaged him in conversation about his occupation as a farmer, and was able to use this knowledge to help the patient to get out of bed in the morning:

Talking about that big heavy load of work he had done in loading his hay away...in trying to get him out of bed, for example telling him I needed a hand to get this hay loaded.

\section{Example 2}

A participant described how a patient hearing all the commotion around her thought she was back at school. The nurse kept telling her that she was in hospital, but that did not work. So she decided to 'switch to the school mode':

'Okay, now it's time for lunch, all the students are eating lunch.' You know, really tapping into her procedural memory of 'you're in school and now it's lunchtime'.

There were also other examples of the use of patients' procedural memories to achieve a positive end.

From the many examples given by participants it was clear that both types of memory (emotional and procedural) were used at the same time. One gave an example of someone who did not want to eat. The nurse engaged her in a conversation about whether the patient used to bake with her mother. The patient began to tell 'how it was with her mum', and in the meantime she started eating and forgot that she did not want to eat. The nurse put the spoon in her hand and the patient did the 'mechanical motion'.

Probing into someone's past can be intrusive, threatening and even patronizing. One participant explained how she avoided this direct approach and instead talked about her own experience, with the hope that the patient would join in and 'open up' if she wanted to.

She was also aware that reaching for the IM of patients might be risky as 'you don't know what emotions were experienced and you are actually taking a risk to do that, because you could actually get some emotions that you don't want'.

\section{Use of 'props'}

Participants reported using a variety of materials to stimulate the memories of people with dementia. These included food, stuffed animals, music, pictures, photographs and books. They were aware of the need to use other strategies than audiovisual aids. For example, the smell of 'food' (e.g. pumpkin pie) or a particular brand of soap was used to stimulate their senses. Talking about football or baking seemed to produce positive reactions.

Experienced nurses seemed more thoughtful in their use of props. One explained how two students were using pictures and newspapers to stimulate distant memories of a patient who was getting bored and frustrated. The participant suggested that the patient (an ex-farmer) be taken for a walk on the grounds of the hospital:

We were able to walk into the grounds of the hospital and we were able to walk on the grass, where it was damp and moist under our 
feet. We were able to kick leaves, to feel the wind, and the patient began to talk about the weather forecast and the hours of light that were left and about the cold.

Interviewees were also aware of the limitations of using props because of patients' short spans of concentration:

You talk about the photographs and sort of talk about the family and that you do get a response back, but there again the attention...that only works for only a very short time.

They varied their priming strategies to overcome the lack of concentration (e.g. moving from talking about 'grandchildren' to reminiscing about 'baking'). There were also occasions when props or cues had to be hidden to avoid negative behaviour, thus removing the stimulus.

According to these expert nurses, the effective and meaningful use of the IM of patients with dementia in achieving mutual positive outcomes depends on 'knowing the patient', 'working within the patient's worldview' and 'using sensitive and patient-centred interactional skills'.

\section{Knowing the patient}

All participants recognized the need to know the patient before intervening in the crisis. This knowledge was mainly in three overlapping parts: background and history of the patient (prior to admission), knowledge of patient in hospital/nursing home, and knowledge of what might have led to the situation.

The background of the patient seemed to be crucial in deciding the intervention. This knowledge was mainly about where they came from, their occupation, their likes and dislikes. It was obtained mainly from relatives and to some extent from the patient themselves:

When I say we used our knowledge and understanding, it was first and foremost where he had come from...a very rural area. He was a farmer - he would have not have been used to women and quite a number of staff, as you can appreciate, were female.

Referring to an example when a patient refused to have a bath, one interveiwee explained:

I would have liked to have known just what her pattern of use of a bath or shower was prior to her admission to the nursing home.

There was a need for in-depth understanding of their background. One participant was not satisfied just knowing that a patient 'liked birds' - she wanted to know the degree and nature of her involvement with birds. For example, was she a biologist who studied birds or did she just like watching them? She wanted more than a superficial knowledge of the patient.
Interactions with patients in a ward or nursing home helped nurses to construct a profile, in particular of their behavioural patterns and moods. Assessment was also deemed necessary in order to understand what could have led to or cause the behavioural crisis. Other participants would look for evidence of pain and assess vision, hearing and ability to understand.

\section{Working within the patient's worldview}

There was a strong recognition of the need to work with the patient and to understand 'what is meaningful to the patient'. This is more than just treating the person as an individual: it is about entering the person's world. Referring to a patient who believed that she was in a different place and time (than she was), one participant explained:

From the patient's point of view, it was just tapping into something that was so meaningful for her. And I think it made a difference for her because we weren't pushing her to say 'today is December'. She didn't care.

Working within the patient worldview meant going against textbook prescriptions such as reality orientation:

We were trying to work within his worldview and to always keep on the side, that yes, there are rules. You need to - I hate to use the expression 'think outside of box'... be idiosyncratic in the way you are thinking about the person.

A recurrent subtheme was that of the patient coming first and the task second. These expert nurses recognized that the task (such as giving a patient a bath) did not have to be achieved at all costs, and that it could be done at a different time.

This focus on an individual patient and their worldview influenced the approaches that were used to tackle behavioural crises. Referring to a case where an 80-year-old patient used to get on a chair to change light bulbs, one participant explained that they made this activity more secure rather than preventing him 'going about his business'.

\section{Using patient-sensitive interactional skills}

Giving patients space and time were also thought to help in these behavioural crises. Voice, tone and the direction from which to approach patients were all underpinned by the notion that they were not to be disturbed, rushed, opposed or forcibly brought to nurse's reality:

I think a lot of it would be due to the way that you would initially approach him...I think you would have been using an appropriate voice and tone with him and some form of touch as reassurance. I use 
a lot of touch, I walk with them...it's more of being with them when they're agitated.

\section{Sources of knowledge}

When making decisions about the use of implicit memories, these expert nurses used the following types of knowledge: experiential, ethical, theoretical and intuitive.

\section{Experiential knowledge}

Experiential knowledge seemed to be their main source (learning on their job), as the following quote illustrates:

...feed them something before they go to bed; the last meal here is 8 O'clock and they don't go to bed until $1 \mathrm{AM}$, and their stomach would be empty, so you have to feed them something. We find that this works.

Learning from one's own and from others' previous experiences was found to be useful:

I think, before, in earlier stages I would have insisted in trying to promote physical hygiene. I think that, as my own career has developed, I have seen other people who have taken different approaches where there has been no insistence on physical hygiene, or limited insistence in caring for the physical aspects of the patient.

In learning from previous experience there was recognition of nurses' limitations:

We wouldn't have understood the difference in someone who was presenting for the first time and someone who was in, maybe, stage 3 or 4 who was very confused...It was difficult because we didn't really understand...so I think, yes, the more we understand the better we are able to help.

\section{Ethical knowledge}

An important source of knowledge that guided nurses' actions and reactions came from their ethical beliefs. In trying to 'persuade' a patient have a bath, some participants would have balanced the need for hygiene and the patient's own standards of hygiene and their right to refuse a bath or shower. Some found it unethical to force patients to live in the nurse's reality rather than their own. Talking down to patients was perceived as unethical.

One participant reported that nurses on her ward based their practice on their religious beliefs:

There was a deeply religious conviction that the care of these people was a mandate and that people would be cared for - meaning we were going to do whatever it takes to make them happy and comfortable, and that did not mean them doing necessarily what we wanted them to do.

\section{Theoretical knowledge}

Participants in this study could name only three nursing theories: 'Orem', 'Lawton's Environmental' and 'Rogers'. They admitted that they did not intentionally focus on theories. Theories 'got embedded' in their practice and, at the time of decision-making, they were not conscious of their use:

I mean, if you are saying to me, would I stop and think which theory would be important here or which research findings, I would say to you that the answer is probably 'No'.

\section{Intuition}

Participants reported using all their senses to assess and react to situations. This could be described as the 'art of caring'. There were many examples of the use of intuition, such as:

...if you are attending to a patient and a simple thing like propping up a pillow. You prop the pillow up and you ask 'Are you OK?' And the patient says, 'Yes', but due to instinct or intuition you don't leave and you continue to prop that pillow up again and to re-ask the question.

\section{Reflective practice}

Interviewees explained how the use of IM and drawing from a range of knowledge sources were underpinned by reflective practice. There were many examples of 'back' and 'forth' movements in their decision-making processes, similar to Schon's (1983) notion of 'reflection in action', and also instances of 'reflection on action' (i.e. after the event). For example:

I try to reflect in a meaningful way both in what I am doing and after what I have actually done. I think it is easier if you can focus your mind in reflecting after events...I think sometimes it can be a bit more difficult when you are in the middle of something, because quite a lot of human behaviour is quite spontaneous.

Participants had to reflect on situations in which they had to move from their reality (i.e. actual time and place) to the patient's reality (i.e. the world they were in).

The principles and processes of using the IM of patients is depicted in Figure 1, which is a synthesis of the themes and subthemes from data collected.

\section{Profile of expert nurses in this study}

These expert nurses were confident to change rules or move outside boundaries by doing new things. They were aware that outcomes might be uncertain and they resorted occasionally to 'trial and error'. They recognized their own limitations by not persisting when they were not successful 


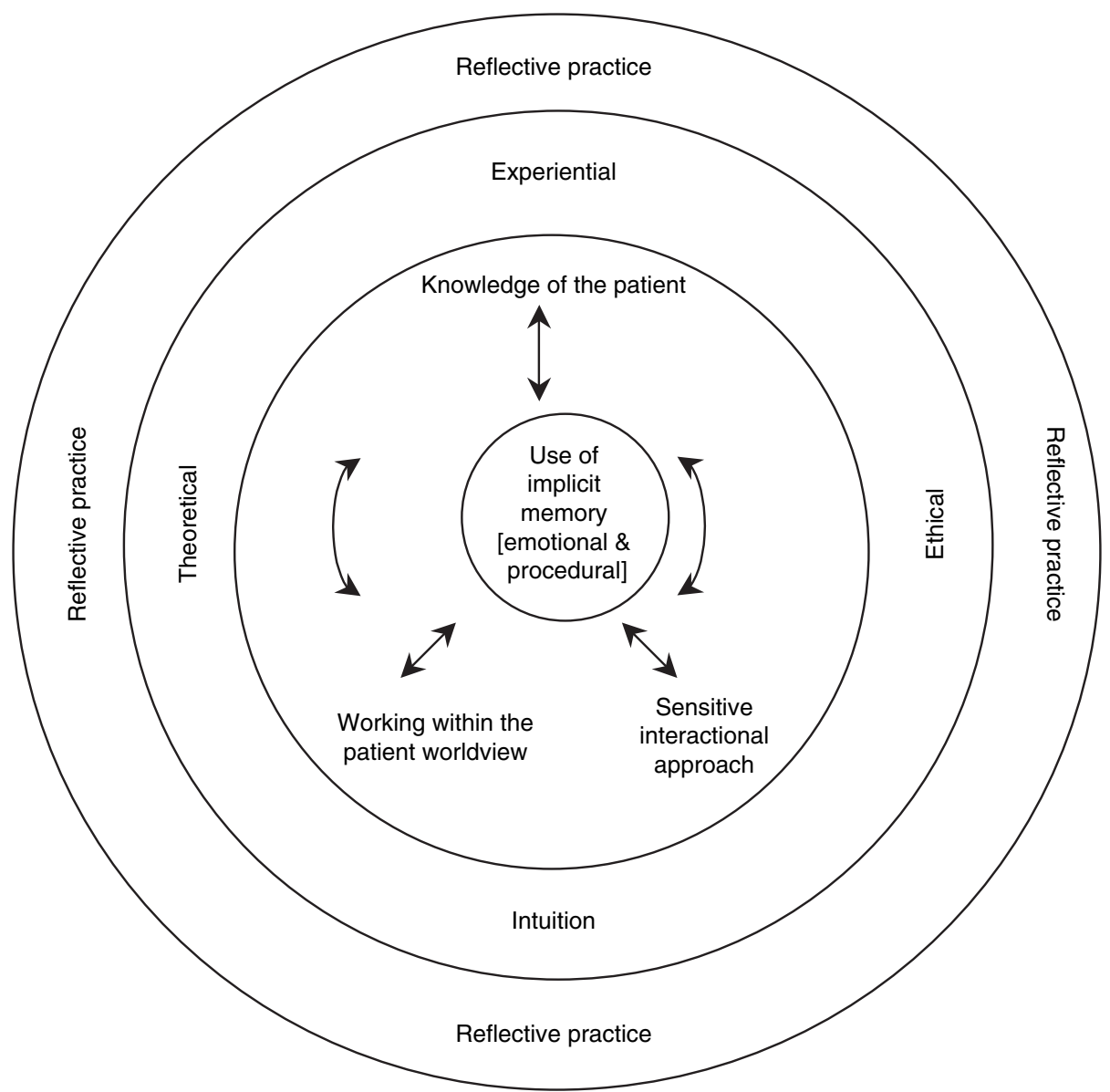

Figure 1 The principles and processes of expert nurses' use of implicit memory of patients with dementia.

in changing behaviour and by trying again later or letting someone else attend to the patient. They were able to use different types of memory, often switching from one to the other (and back), and to recognize the benefits and limitations of different types of memory. They drew significantly from experiential knowledge but also from other sources. Above all, they put patients first and the tasks second.

\section{Differences in responses between the USA and NI samples}

Nurses in both samples were similar in their use of IM and their perceptions of the benefits of this. There were no differences in the 'props' they used or in the way in which they used them. They drew from the same range of knowledge sources, but those from the USA were able to name relevant theories. In their assessment of patients, the USA nurses seemed to put more emphasis on physical and physiological factors and on drug reactions. Those in NI wanted to know more about the background of patients and their patterns of behaviour.

\section{Discussion}

\section{Use of implicit memory}

Our findings show how, when and to what ends expert nurses use IM in the care of patients with Alzheimer's disease. Their use of the term 'long-term memory' to describe all forms of IM and the difficulty (of some participants) in differentiating between emotional and procedural memory may, however, hinder their full appreciation of different types of memory. In their defence, they pointed out that they use both in the same situations.

\section{Knowledge sources}

It was clear that while they drew from a range of knowledge sources, they relied heavily on their own and others' experiences. Although they used other forms of knowledge, such as ethical, theoretical and intuitive, these seemed to be embedded in their sum total of knowledge and were not always used at a conscious, rational level. Experiential 


\section{What is already known about this topic}

- The inability of nurses to prevent aggressive behaviour by patients with Alzheimer's disease can lead to inappropriate interventions.

- Caring for people with dementia is a complex process requiring delicate interpretive work.

- Implicit memory remains relatively intact throughout the progression of Alzheimer's disease.

\section{What this paper adds}

- Nurses use implicit memories (both procedural and emotional) in the care of patients with Alzheimer's disease.

- Nurses use interventions based on a range of knowledge sources and underpinned by reflective practice.

- More research is needed to test nursing interventions building on implicit memories in this group of patients.

knowledge, on the other hand, provided the conscious rationale for most of their decisions.

The findings show the prominent part which ethical reasoning plays in the care of these patients. This is similar to what Benner (1991) calls the 'ethical comportment', which she describes as the 'embodied, skilled know-how of relating to others in way that are respectful and support their concerns' (p. 2).

None of our participants referred to research findings to explain and justify their decisions. Although this was not a study of research utilization, we would have expected expert nurses to refer to some of the literature that they had read.

Differences in the data collected from the samples of nurses in the two countries were twofold. Michigan nurses named some of the theories they reported using in their practice, while their Northern Irish counterparts did not. In their assessments the factors leading to unusual behaviour, Northern Irish nurses put more emphasis on knowing how patients perceived the situation, while those from Michigan stressed more the importance of physical assessment and the effects of drugs. Although this may have reflected differences in education programmes, we must caution against generalization as this was not the purpose of the study.

\section{Attributes of expert nurses}

Our data reveal a picture of expert nurses as confident practitioners able to access what was embedded in the unconscious memory of patients and use it to communicate meaningfully with them. Expert nurses realized that on occasions the nurse and patient existed in parallel universes that they were visitors in the patient's universe rather than vice versa. They performed expert holistic assessments, used themselves in therapeutic ways, trusted their intuition and realized that their patients needed to be treated as whole persons, not just as scores on mental status examinations. Further, these expert nurses were risk-takers who demonstrated 'thinking in action' and 'thinking on action'. They gave themselves the freedom and space to explore, used all kinds of preserved memories, and were able to devise interventions based on them. They suspended the rules and were creative.

They were also aware of their own shortcomings and the limitations of their interventions. Although this study did not involve novice nurses, the participants were able to reflect the difference on how they felt and behaved when they were 'novices' and how they had 'moved on'. This supports Berg et al.'s (1998) earlier findings on how nurses built up their experience and confidence.

The attitudes of expert practitioners which this study revealed also fit Benner et al.'s (1992) four aspects of expert practice, namely reliance on past, concrete experience rather than on abstract principles and rules; reliance on intuition rather than analytic, rule-based thinking; viewing the situation holistically and being fully involved rather than remaining detached.

\section{Study limitations}

A larger sample would have yielded a more meaningful comparison between nurses from these two countries. With hindsight, the lack of reference to the literature and to research findings by participants should have been probed further. The extent to which practice reported in the interviews represents reality is not known, and observations might have given a different perspective.

\section{Conclusion}

These findings give an indication that IM can be used with positive effects. Nurses should be educated and encouraged to maximize the potential of IM in the care of people with dementia. Our findings reinforce the value of 'knowing the patient' and the need to focus on patients' wishes and needs rather than on nursing tasks.

The findings have several implications for future research. First, we focused on expert nurses but a comparative study with novice nurses would identify the types of nursing 
knowledge they use and areas of knowledge that need to be developed further. The results would be meaningful for curricular development in both countries. Secondly, recent research has shown that the brains of people with dementia still have areas that can support high level, complex thinking, and these areas can change with learning (Loewenstein et al. 2004). Nursing research focused on clinical trials of interventions linked to those areas of the brain that support IM could incorporate strategies illuminated by the expert nurses in this study.

\section{Acknowledgement}

This study was supported by a Fulbright Distinguished Visiting Professor Award, 2001-2002, to Professor A. Whall.

\section{References}

Bachevalier J. \& Mishkin M. (1984) An early and a late developing system for learning and retention in infant monkeys. Behavioural Neuroscience 98(5), 770-778.

Benner P. (1984) From Novice to Expert: Excellence and Power in Clinical Nursing Practice. Addison-Wesley, Menlo Park, California.

Benner P. (1991) The role of experience, narrative, and community in skilled ethical compartment. Advanced in Nursing Science 14(2), $1-21$.

Benner P., Tanner C. \& Chesla C. (1992) From beginner to expert: Gaining a differentiated clinical world in critical care nursing. Advances in Nursing Science 14(3), 13-28.

Berg A., Hallberg I.R. \& Norberg A. (1998) Nurses' reflections about dementia care, the patients, the care and themselves in their daily caregiving. International Journal of Nursing Studies 35, 271-282.

Burke J.R. \& Morgenlander J.C. (1999) Managing common behavioural problems in dementia. Postgraduate Medicine 106(5), 131140.

Camus J.F., Nicolas S., Wenisch E., Morrone I., Blanchard F. \& Bakchine S. (2001) Implicit memory for words presented in short texts is preserved in Alzheimer's disease. Revue Neurologique 157(Suppl. 10), 52.

Christensen H. \& Birrell P. (1991) Explicit and implicit memory in dementia and normal ageing. Psychological Research 53, 149-161.

Colaizzi P. (1978) Psychological research as the phenomenologist views it. In Existential Phenomenological Alternative for Psychology (Walle R. \& Kings M., eds), Oxford University Press, New York, pp. 48-71.

De Vreese L.P., Neri M., Fioravanti M., Belloi L. \& Zanetti O. (2001) Memory rehabilitation in Alzheimer's disease: a review of progress. International Journal of Geriatric Psychiatry 16(8), 794 809.

Eriksson C. \& Saveman B.I. (2002) Nurse's experience of abusive/ non-abusive caring for demented patients in acute care settings. Scandinavian Journal of Caring Sciences 16, 79-85.

Giorgi A. (1985) Phenomenology and Psychological Research. Duquesne University Press, Pittsburg, Pennsylvania.

Graf P. \& Masson M.E.J. (1993) Implicit Memory: New Directions in Cognition, Development, and Neuropsychology. Lawrence Erlbaum Association, Hillsdale, New Jersey.

Hallberg I.R. \& Norberg A. (1990) Staff's interpretation of the experience behind vocally disruptive behavior in severely demented patients and their feelings about it - an explorative study. International Journal of Aging and Human Development 31(4), 295305.

Halpern A.R. \& O'Connor M.G. (2000) Implicit memory performance of patients with Alzheimer's disease. Neuropsychology 14(3), 391-397.

Jansson L. \& Norberg A. (1992) Ethical reasoning among registered nurses experienced in dementia care. Scandinavian Journal of Caring Sciences 6(4), 219-227.

van Kaam A. (1966) Existential Foundations of Psychology. Duquesne University Press, Pittsburgh, Pennsylvania.

Lai C.K.Y. \& Arthur D.G. (2003) Wandering behaviour in people with dementia. Journal of Advanced Nursing 44(2), 173-182.

Le Doux J.E. (1993) Emotional memory systems in the brain. Journal of Brain Research 58, 69-79.

Loewenstein D.A., Acevedo A., Czaja S.J. \& Duara R. (2004) Cognitive rehabilitation of midly impaired Alzheimer disease patients on cholinesterase inhibitors. American Journal of Geriatric Psychiatry 12(4), 395-402.

Mishkin M. \& Petri H.L. (1984) Memories and habit: some implications for the analysis of learning and retention. In $\mathrm{Neu}$ ropsychology of Memory (Butters N. \& Squire L.R., eds), Guildford, New York, pp. 287-296.

Morse J. \& Field P.A. (1996) Nursing Research: The Application of Qualitative Approaches, 2nd edn. Chapman and Hall, London.

Norberg A. (1996) Caring for demented patients. Acta Neurologica Scandinavia 165, 105-108.

Powers B.A. (2004) Ethnographic analysis of every day ethics in the care of nursing have residents with dementia. Nursing Research 50(6), 332-339.

Schon D. (1983) The Reflective Practitioner. Basic Books, New York. Slizewski D. (1998) The Use of Implicit Memory in Later Stage Dementia in Late Stage Dementia. Master Research Project, the University of Michigan, School of Nursing, Ann Arbor, Michigan.

Son G.-R., Therrien B. \& Whall A. (2002) Implicit memory and familiarity among elders with dementia. Journal of Nursing Scholarship 34(3), 263-267.

Verfaellie M., Keane M.M. \& Johnson G. (2000) Preserved priming in auditory perceptual identification in Alzheimer's disease. Neuropsychologia 38(12), 1581-1592. 